DOI 10.37882/2223-2974.2020.12-2.04

\title{
О СПЕЦИФИКЕ ОБЪЕКТИВНОЙ СТОРОНЫ ПРЕСТУПНОГО МОШЕННИЧЕСТВА В СФЕРЕ ЗАКУПОК ТОВАРОВ, РАБОТ И УСЛУГ ДЛЯ ГОСУДАРСТВЕННЫХ И МУНИЦИПАЛЬНЫХ НУЖД
}

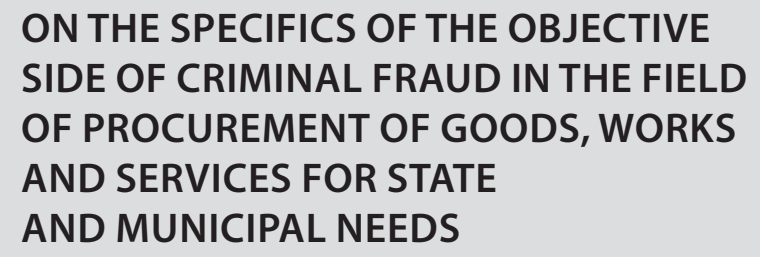

A. Gudkov

Summary: Fraud in the procurement of goods, works, services for state and municipal needs (public procurements) has a specific character that manifests itself in all elements of a crime. This article proposes to consider the features of the objective side of this crime. Analysis of the theoretical works and judicial practice revealed three main features of the objective side of the fraud in the field of public procurement. Firstly, there is a great variety of actions to create conditions for committing a crime: collusion between procurement participants and procurement organizers, violations in the preparation of procurement documentation, formation of a contract with an inflated initial (maximum) price, etc. The second and main feature is to simulate the delivery of goods, the performance of work or the provision of services; the supply of goods, the performance of work or the provision of the services at an inflated cost, or the supply of cheaper goods, the performance of cheaper work or the provision of cheaper services. The third feature is related to the precise definition of the moment when the crime ends, since in some cases the theft is accompanied by various actions aimed at disguising the crime committed. The revealed features of the objective side of the considered crime allow us to understand its specifics, which has theoretical and practical significance.

Keywords: fraud, state (municipal) procurement, objective side, collusion, supply, tender, overpriced, falsification of documents, contract, budget.
B последние годы теоретики уголовного права России особое внимание уделяют изучению проблем уголовно-правовой оценки мошенничества в сфере закупок товаров, работ, услуг для государственных и муниципальных нужд (публичных закупок), что обусловлено рядом причин, в числе которых: существенное увеличение количества зарегистрированных преступлений, связанных с публичными закупками; значительно возрастающая динамика причиненного ущерба от хищений государственного и муниципального имущества; совершение преступления в специфической сфере общественных отношений, специальными субъектами, а также особыми способами [1, с. 108].
Гудков Антон Павлович

следователь по особо важным делам, Следственный комитет Российской Федерации по Магаданской области an_gudkov@rambler.ru

Аннотация: Мошенничество в сфере закупок товаров, работ, услуг для государственных и муниципальных нужд (публичных закупок) обладает спецификой, которая проявляется во всех элементах состава преступления. В настоящей статье предлагается рассмотреть особенности объективной стороны данного преступления. Анализ теоретических работ и судебной практики позволил выявить три основные особенности объективной стороны мошенничества в сфере публичных закупок. Во-первых, большим многообразием обладают действия по созданию условий для совершения преступления: сговор между участниками закупок и организаторами закупок, нарушения при подготовке документации о закупке, формирование контракта с завышенной начальной (максимальной) ценой и т.д. Вторая и основная особенность заключается в имитации поставки товаров, выполнения работ или оказания услуг; поставки товаров, выполнения работ или оказания услуг по завышенной стоимости либо поставки более дешевых товаров, выполнении более дешевых работ или оказании более дешевых услуг. Третья особенность связана с точным определением момента окончания преступления, поскольку в ряде случаев хищение сопровождается различными действиями, направленными на маскировку совершенного преступления. Выявленные особенности объективной стороны рассмотренного преступления позволяют уяснить его специфику, что имеет теоретическое и практическое значение.

Ключевые слова: мошенничество, государственные (муниципальные) закупки, объективная сторона, сговор, поставка, конкурс, завышенная цена, фальсификация документов, контракт, бюджет. 
случае, как правило, выступает стремление обеспечить в конкурсной процедуре незаконную победу заранее определенного поставщика, с которым впоследствии будет заключен государственный или муниципальный контракт.

А.Ю. Бочкова выделяет два вида сговоров, встречающихся на рынке госзаказа: между участниками закупок (картельный сговор), между участниками закупок и организаторами закупок (заказчиком, в т.ч. членами комиссии, уполномоченным органом, специализированной организацией) [3, с. 117-119]. Второй из отмеченных видов сговора наиболее часто встречается в судебной практике по делам рассматриваемой категории. Одной из распространенных форм реализации преступного сговора при совершении рассматриваемой разновидности мошенничества является подыскание организатором закупки подконтрольной ему коммерческой организации для участия в конкурсных процедурах и создание условий для ее победы. Условия для победы такой организации создаются путем выполнения комплекса незаконных действий по подготовке документации для участия в конкурсных процедурах, направленных на ограничение конкуренции.

Так, одним из распространенных способов ограничения конкуренции является излишняя детализация в документации о закупке продукции технических требований, которые способен удовлетворить исключительно определенный поставщик. Для данной категории рассматриваемого преступления также характерен и такой незаконный прием ограничения конкуренции как укрупнение заказа. В этом случае в один заказ (лот) включается намеренно большое число разнообразного оборудования, которое технологически и функционально никак не связано между собой. Ещё одно типичное нарушение при составлении документации об участии в конкурентных процедурах - это формирование контракта с завышенной начальной (максимальной) ценой. Для этого, как правило, используются коммерческие предложения от поставщиков, содержащие завышенную цену предложения на закупаемую продукцию.

Так, например, К. признан судом виновным в совершении мошенничества при закупке оборудования станции обезжелезивания питьевой воды на водозаборном узле при следующих обстоятельствах. К., будучи заместителем главы администрации района, дал своим подчиненным указание подготовить комплект документов для участия в открытом аукционе с использованием сведений, предоставленных соучастником. Подчиненные работники, выполняя указание К., получили от его соучастника по электронной почте письмо со светокопиями коммерческих предложений на поставку оборудования станции для обезжелезивания с завышенной стоимостью от подконтрольных соучастнику юридических лиц.
Будучи введенными в заблуждение относительно стоимости оборудования и умысла соучастников, работники администрации сформировали завышенную начальную (максимальную) цену по трем муниципальным контрактам. Как установлено судом, мошенник использовал и другой способ, который облегчил совершение преступления: было осуществлено дробление закупки на три контракта так, чтобы каждый из них был заключен на сумму ниже 10 млн.руб. Это позволило виновному уйти от дополнительного контроля со стороны Комитета по конкурентной политике [4].

В другом случае виновный, являясь членом конкурсной комиссии, намеренно не указал в конкурсном извещении начальную максимальную цену контракта с целью создать условия для участия и победы в конкурсе «подставной» фирмы [5].

Одним из способов обеспечения незаконной победы нужной организации в конкурсных процедурах является предоставление в комиссию подложных документов о соответствии участника предъявляемым требованиям (лицензии, свидетельства о допуске к определенным видам работ и пр.). Еще одним способом незаконно повлиять на выводы комиссии при проведении конкурсных процедур является предоставление в комиссию так называемых авторизационных писем, свидетельствующих о том, «нужный» участник является партнером-дилером фирмы-производителя в России и единственным («эксклюзивным») поставщиком, осуществляющим поставки определенного оборудования. Такие письма могут быть либо поддельными, либо настоящими, полученными по договоренности с фирмой-производителем. В действительности же «партнер-дилер» никакими эксклюзивными качествами не обладает и ничем не отличается от обычного продавца, приобретающего и продающего товары.

Как отмечал С.А. Черняков, мошенничество в сфере закупок может быть связано с предоставлением государственным и муниципальным заказчикам поддельных или необеспеченных банковских гарантий. В таких ситуациях реальное обеспечение исполнения государственных и муниципальных контрактов отсутствует [6, с. 140].

Другая особенность объективной стороны мошенничества в сфере публичных закупок заключается в совершении умышленных действий, непосредственно связанных с осуществлением поставки товаров, выполнением работ и оказанием услуг по государственному или муниципальному контракту. Это может быть, к примеру:

- имитация поставки товаров, выполнения работ, оказания услуг путем изготовления фиктивных документов и иных действиях, при фактическом отсутствии поставки товаров, выполнения работ или оказания услуг, 
- поставка товаров, выполнение работ, оказание услуг по завышенной стоимости,

- поставка более дешевых товаров, выполнение более дешевых работ, оказание более дешевых услуг.

Имитация поставки товаров, выполнения работ, оказания услуг означает выполнение комплекса действий по созданию видимости поставки товаров, выполнения работ, оказания услуг, при фактическом ее отсутствии. К таким действиям, как правило, относится изготовление фиктивных документов. Свидетельство подобным деяниям можно встретить и в судебной практике.

Так, суд признал Г. виновным в совершении мошенничества, связанном с поставкой стройматериалов для нужд лечебного учреждения. Подсудимый Г., будучи представителем Заказчика, попросил своего знакомого учредителя коммерческой организации, принимавшего участие в аукционе, снизить цену контракта в целях победы на аукционе. После победы указанной организации Г. обеспечил заключение с ней государственного контракта. Затем Г. попросил свою мать, являвшуюся директором указанной коммерческой организации (Поставщика), изготовить фиктивные документы, свидетельствующие о поставке стройматериалов - счета-фактуры и товарные накладные. После изготовления и подписания ею указанных документов Г., как представитель Заказчика, сам подписал данные фиктивные документы, свидетельствующие о приемке якобы поставленного товара. После поступления денежных средств по государственному контракту на счет аффилированной коммерческой организации Г. получил возможность распоряжаться ими по своему усмотрению [7].

При поставке товаров по завышенной стоимости поставка товара фактически производится, однако цена поставляемого товара искусственно завышается обвиняемыми. Разница между стоимостью товара, выделяемой из средств бюджета, и фактической стоимостью, по которой товар приобретается у поставщика (изготовителя), присваивается и является ущербом.

Наконец, поставка более дешевых товаров, выполнение более дешевых работ, оказание более дешевых услуг означает, что поставляются товары (выполняются работы), не предусмотренные контрактом, а более дешевые, разница в их стоимости неправомерно присваивается. Подобные случаи наиболее распространены в строительной сфере, где производится множество скрытых работ, и выявить факт их удешевления представляет значительную сложность.

Третья особенность объективной стороны мошенничества в сфере публичных закупок заключается в специфике момента окончания преступления. Так, со- гласно пункту 5 Постановления Пленума Верховного Суда Российской Федерации № 48 от 30 ноября 2017 года «О судебной практике по делам о мошенничестве, присвоении и растрате» мошенничество признается оконченным с момента, когда имущество поступило в незаконное владение виновного или других лиц, и они получили реальную возможность (в зависимости от потребительских свойств этого имущества) пользоваться или распорядиться им по своему усмотрению. В этом же пункте названного Постановления высший судебный орган разъясняет, что хищение безналичных денежных средств «...следует считать оконченным с момента изъятия денежных средств с банковского счета их владельца или электронных денежных средств, в результате которого владельцу этих денежных средств причинен ущерб» [8]. Из приведенного разъяснения следует, что Пленум Верховного Суда Российской Федерации конкретизировал момент окончания хищения безналичных денежных средств путем указания на изъятие их с банковского счета их владельца. Формулировку «в результате которого ... причинен ущерб» можно понимать как получение виновным реальной возможности пользоваться и распоряжаться указанными денежными средствами по своему усмотрению. Изученные нами материалы судебной практики по делам о мошенничестве в сфере публичных закупок свидетельствуют о том, что в отдельных случаях изъятие безналичных денежных средств с банковского счета их владельца совпадает по времени с зачислением их на банковский счет виновного и получением им реальной возможности пользоваться и распоряжаться указанными денежными средствами по своему усмотрению [9].

Но встречаются и ситуации, когда между двумя указанными событиями имеется временной промежуток, обусловленный спецификой некоторых хищений, маскировкой виновными своих действий. Кпримеру, К. являлся директором акционерного общества «3.», учредителем и единственным акционером которого является Российская Федерация в лице Государственной корпорации «Ростех». Действуя в составе организованной группы, К. обеспечил победу АО «3.» в аукционе на поставку быстровозводимых войсковых фортификационных укреплений и заключение государственных контрактов с Министерством обороны Российской Федерации. После этого участники организованной группы приняли фиктивное решение финансовой комиссии о неудовлетворительном финансовом положении $\mathrm{AO}$ «3.» и передаче исполнения контрактов подконтрольной фирме-однодневке ООО «К.». В дальнейшем участники организованной группы обеспечили перечисление на счет указанной фирмы авансовых платежей, обеспечив привлечение и поступление денежных средств от Министерства обороны Российской Федерации на счета $A O$ «3.» на сумму 13,2 млн.руб. Из указанной суммы на изготовление быстровозводимых войсковых фортификационных укре- 
плений участники организованной группы затратили 8,5 млн.руб. После этого АO «3.» перечислило на расчетные счета ООО «К.» оставшуюся сумму по государственным контрактам в размере 10,9 млн.руб. Оставшаяся на расчетных счетах ООО «К.» сумма в размере 15,6 млн. руб. была перечислена на лицевые счета шестерых физических лиц подконтрольных членам организованной группы, а также на счета двух аффилированных юридических лиц, с указанием несоответствующего действительности основания перечислений «оплата за комплектующие к ГНТ-1 и ГНТ-2». Перечисленные на счета подконтрольных физических лиц и фиктивных хозяйствующих субъектов указанные денежные средства были обналичены и распределены между членами организованной группы [10]. В приведенном примере имеется значительный временной разрыв между перечислением платежей на счет ООО «К.» (изъятие денежных средств со счета владельца) и распределением похищенных денежных средств между членами организованной группы.

В данном случае, если исходить из позиции высшей судебной инстанции, моментом окончания преступления следует считать перечисление на счет ООО «К.» последней денежной суммы, предназначенной для оплаты по государственным контрактам. Дальнейшие действия, связанные с перечислением денежных средств подконтрольным физическим и юридическим лицам, обналичивание и распределение между членами преступной группы являются посткриминальным поведением, выходят за рамки объективной стороны и направлены на сокрытие преступления.

Изложенное подтверждает, что объективная сторона мошенничества в сфере публичных закупок имеет и такую специфическую особенность, которая сопряжена с точным определением момента окончания

\section{такого преступления.}

В заключение следует отметить, что именно вторая из выявленных особенностей объективной стороны рассматриваемого преступления - совершение умышленных действий, непосредственно связанных с осуществлением поставки товаров, выполнением работ и оказанием услуг по государственному или муниципальному контракту, и позволяет наиболее точно определить суть мошенничества в сфере публичных закупок.

С учетом изложенного, объективную сторону мошенничества в сфере публичных закупок можно определить как хищение бюджетных денежных средств, выделенных на закупку товаров, работ или услуг для государственных или муниципальных нужд, совершенные путем обмана и (или) злоупотребления доверием, а также имитации поставки товаров, выполнения работ или оказания услуг; поставки товаров, выполнения работ или оказания услуг по завышенной стоимости либо поставки более дешевых товаров, выполнении более дешевых работ или оказании более дешевых услуг.

Таким образом, выявленные особенности объективной стороны рассмотренного преступления позволяют не только уяснить его специфику, но и учесть её при формулировании определения мошенничества в сфере публичных закупок, что имеет значение для дальнейших теоретических исследований по проблемам его уголовно-правовой оценки. Кроме того, отмеченные специфические признаки мошенничества в сфере публичных закупок раскрывают его сложный характер, а это имеет практическое значение для раннего выявления и пресечения таких преступлений, предотвращению причинения существенного вреда объектам, охраняемым уголовным законом.

\section{ЛИТЕРАТУРА}

1. Трунцевский, Ю.В. Преступления в сфере использования федеральной собственности. Теория и практика противодействия коррупции / Ю.В. Трунцевский // Имущественные отношения в РФ. - 2016. - № 11(182). - С. 106-114.

2. К Краснов, И.В. Эффективность и перспективы уголовно-правовой охраны сферы государственных и муниципальных закупок / И.В. Краснов, Л.О. Герасимова // Известия Юго-Западного государственного университета. Серия: История и право. - 2014. - № 4. - С. 127-131.

3. Бочкова, Ю.А. Сговоры на торгах при осуществлении государственных закупок / Ю.А. Бочкова // Проблемы современной экономики. - 2014. - № 2 (50). - C. $117-120$.

4. Приговор Дмитровского городского суда Московской области от 13.06.2018 по делу № 1-265/2018 [Электронный ресурс] // Sudact.ru. - 28.08.2019. URL: http://sudact.ru/regular/doc/j0j0LmsEK05u.

5. Приговор 235 гарнизонного военного суда (город Москва) от 17.12.2012 по делу № 1-65/2012 [Электронный ресурс] // Sudact.ru. - 25.08.2019. - URL: http://sudact.ru/regular/doc/gulEh1H3vQmv.

6. Черняков, С.А. Предупреждение мошенничества в сфере обеспечения исполнения обязательств банковскими гарантиями: дис. ... канд. юрид. наук / Черняков С.А. - М., 2016. - 274 с.

7. Приговор Первомайского районного суда г. Кирова от 11.07.2018 по делу № 1-172/2018 [Электронный ресурс] // Sudact.ru. - 02.07.2019. - URL: http:// sudact.ru/regular/doc/pJ0kDg5uXgYL.

8. 0 судебной практике по делам о мошенничестве, присвоении и растрате: постановление Пленума Верховного Суда Российской Федерации от 30 ноября 2017 г. № 48 / Пленум Верховного Суда Российской Федерации // Справочная правовая система «Консультант Плюс». Раздел «Судебная практика». 
Информационный банк «Версия Проф».

9. Приговор Центрального районного суда г. Барнаула от 18.06.2018 по делу № 1-13/2018 [Электронный ресурс] // Sudact.ru. - 28.08.2019. - URL: http:// sudact.ru/regular/doc/th8qUsdPY9i.

10. Приговор Володарского районного суда г. Брянска от 26.06.2018 по делу № 1-82/2018 [Электронный ресурс] // Sudact.ru. - 27.08.2019. - URL: http:// sudact.ru/regular/doc//KaNRmHrkLbg.

( Гудков Антон Павлович (an_gudkov@rambler.ru).

Журнал «Современная наука: актуальные проблемы теории и практики»
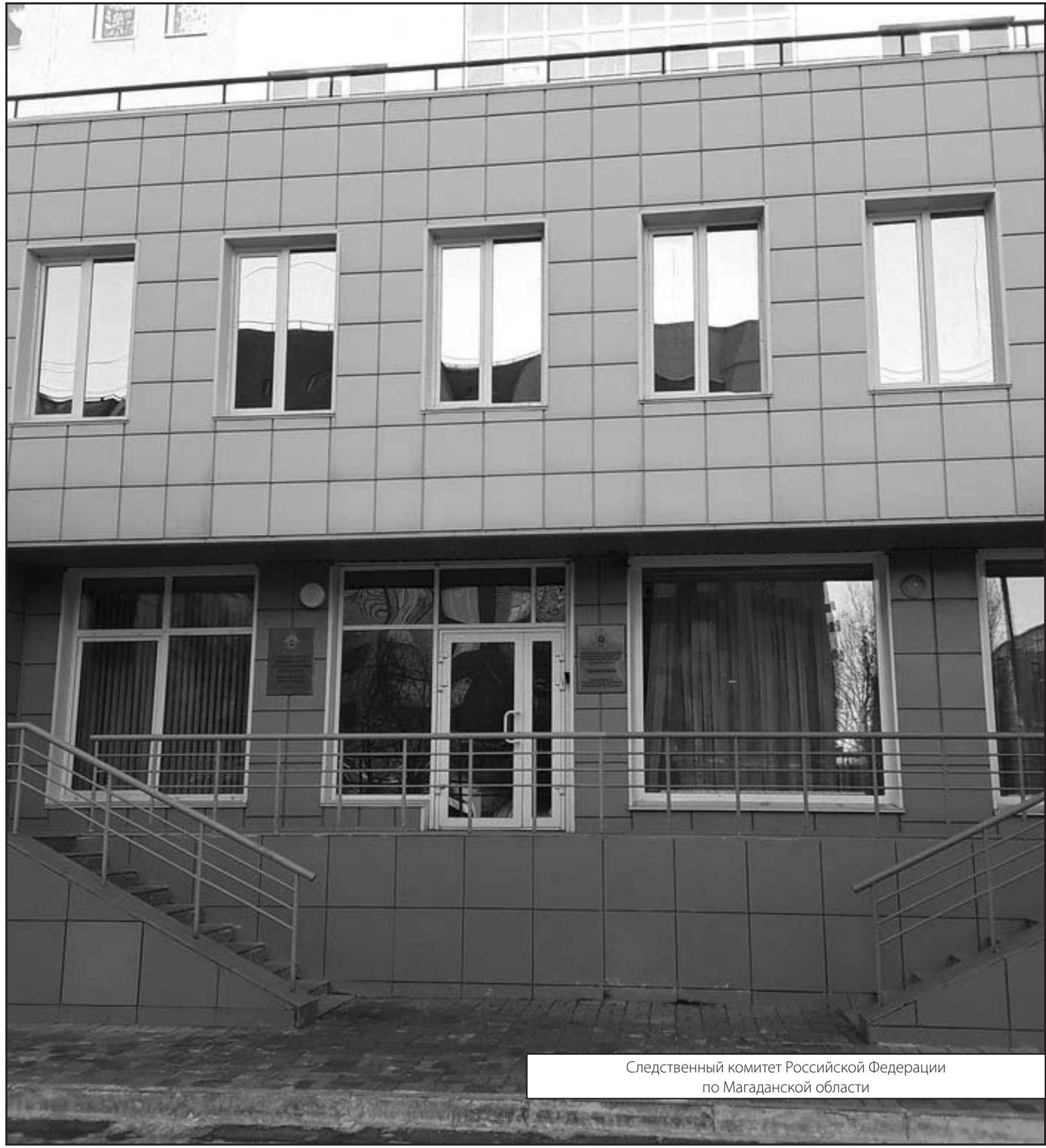